\title{
Correction to: Construction and case verification of rural environmental value-added evaluation system
}

\author{
Ajun Wan ${ }^{1} \cdot$ Xiaolei $\mathbf{Q i}^{1} \cdot$ Weidong Yue ${ }^{1} \cdot$ Runqiu Tu$^{1}$ \\ Published online: 16 September 2021 \\ (c) Springer Nature B.V. 2021
}

\section{Correction to: Environment, Development and Sustainability https://doi.org/10.1007/s10668-021-01508-8}

The authors would like to inform the readers that an error was made in the original article "Construction and case verification of rural environmental value added evaluation system" by "Ajun Wan, Xiaolei Qi, Weidong Yue and Runqiu Tu", the reference "Wan, A., Tu, R., Yue, W. et al. Construction and case study of rural environmental value-added evaluation system based on emergy theory. Environ Dev Sustain 23, 4715-4734 (2021). https://doi. org/10.1007/s10668-020-00729-7" has not be cited both in reference list and in the Fig. 7 caption. The correction caption of Fig. 7 should be changed into "Results of environmental value-added assessment of Queshan village from 2021 to 2015 (Wan et al., 2021)”. The authors apologize for this error and the authors can also confirm that the corrections will not influence the findings and the conclusion of this article.

\section{Reference}

Wan, A., Tu, R., Yue, W., et al. (2021). Construction and case study of rural environmental value-added evaluation system based on emergy theory. Environment, Development and Sustainability, 23, 47154734. https://doi.org/10.1007/s10668-020-00729-7

Publisher's Note Springer Nature remains neutral with regard to jurisdictional claims in published maps and institutional affiliations.

The original article can be found online at https://doi.org/10.1007/s10668-021-01508-8.

Ajun Wan

wanajun@tongji.edu.cn

1 Institute of New Rural Development, Tongji University, Shanghai 201804, China 